\title{
Article
}

\section{Transformation of Dilute Ethylene at High Temperature on Micro- and Nano-Sized H-ZSM-5 Zeolites}

\author{
Antoine Beuque ${ }^{1}\left(\mathbb{D}\right.$, Matthias Barreau ${ }^{1}\left(\mathbb{D}\right.$, Elise Berrier ${ }^{2} \mathbb{D}$, Jean-François Paul ${ }^{2}$, Nuno Batalha ${ }^{1}$, \\ Alexander Sachse ${ }^{1}$ (D) and Ludovic Pinard ${ }^{1, *}$ \\ 1 Institut de Chimie des Milieux et Matériaux de Poitiers (ICM2P), UMR 7285 CNRS, 4 Rue Michel Brunet, \\ Bâtiment B27, CEDEX 9, 86073 Poitiers, France; Antoine.beuque@univ-poitiers.fr (A.B.); \\ mbarreau@unistra.fr (M.B.); nbatalha@gmail.com (N.B.); alexander.sachse@univ-poitiers.fr (A.S.) \\ 2 French National Centre for Scientific Research (CNRS), Centrale Lille, University Lille, UMR 8181, \\ UCCS—Unité de Catalyse et Chimie du Solide, 59000 Lille, France; elise.berrier@univ-lille.fr (E.B.); \\ jean-francois.paul@univ-lille.fr (J.-F.P.) \\ * Correspondence: ludovic.pinard@univ-poitiers.fr; Tel.: +33-(0)54-945-3905
}

Citation: Beuque, A.; Barreau, M.; Berrier, E.; Paul, J.-F.; Batalha, N.;

Sachse, A.; Pinard, L. Transformation of Dilute Ethylene at High Temperature on Micro- and Nano-Sized H-ZSM-5 Zeolites. Catalysts 2021, 11, 282. https:// doi.org/10.3390/catal11020282

Academic Editor: Sung Hwa Jhung

Received: 26 January 2021

Accepted: 18 February 2021

Published: 21 February 2021

Publisher's Note: MDPI stays neutral with regard to jurisdictional claims in published maps and institutional affiliations.

Copyright: (c) 2021 by the authors. Licensee MDPI, Basel, Switzerland. This article is an open access article distributed under the terms and conditions of the Creative Commons Attribution (CC BY) license (https:// creativecommons.org/licenses/by/ $4.0 /)$.

\begin{abstract}
Ethylene dehydroaromatisation (EDA) was investigated at $700{ }^{\circ} \mathrm{C}$ under 1 bar of ethylene $\left(5 \mathrm{~mol} \%\right.$ in $\mathrm{N}_{2}$ ) over a micro-(M) and a nano-sized (N) H-ZSM-5. On the M zeolite an induction period followed by deactivation was observed, which could be related to the presence of long diffusion path lengths in this sample, leading to mass transfer resistance. During the induction step, the aromatics yield increases, despite a significant loss of the acid site concentration as a result of coking. This induction period corresponds to the formation of an active hydrocarbon pool (HCP) composed of units of 2 to 5 aromatic rings with a molecular weight ranging from 130 to $220 \mathrm{~g} \mathrm{~mol}^{-1}$ (light coke). A kinetic study revealed that the developing HCP species is two times more active than Brønsted acid sites in the fresh zeolite. Diffusion limitations yet impact the product desorption by promoting coke growth and, therefore the deactivation of the HCP and hence of the catalyst. From MA-LDI/LDI-TOF MS (Matrix Assisted Laser Desorption Ionization-Time of Flight Mass Spectroscopy) characterisation was deduced that even after complete catalyst deactivation, the asdeposited coke continues growing at the external surface of the zeolite by condensation reactions, thus leading to heavy coke composed of more than 100 carbon atoms and a molar mass exceeding $1300 \mathrm{~g} \mathrm{~mol}^{-1}$. Unlike the micro-sized zeolite, the nano-scaled zeolite features a short diffusion path length and promotes fast formation of the active HCP. As a result, higher activity and selectivity into benzene were observed, whilst catalyst deactivation was significantly mitigated.
\end{abstract}

Keywords: H-ZSM-5; ethylene; deactivation; coke; hydrocarbon pool; hierarchical zeolite; aromatisation

\section{Introduction}

The landscape for both petrochemical and oil and gas industries is currently evolving towards favouring the production of high value-added chemicals, such as light olefins (ethylene and propylene) and benzene, toluene, and mixed xylenes (BTX) aromatics. The latter are identified as crucial chemical building blocks, due to their heavy use in a broad range of strategic downstream processes. The yearly production of ethylene is one of the highest in organic chemistry, with a global production of 152 billion tons in 2017 [1]. The versatility of ethylene makes it the prime example of a platform chemical. Therefore, ethylene is massively used in chemical transformations for: polymerisations, oxidations, halogenations, alkylations, hydrations, oligomerisations, hydroformylations, and, to a lesser extent, aromatisations. Among the latter, the ethylene dehydroaromatisation (EDA) process appears as a promising route for $\mathrm{C}_{2} \mathrm{H}_{4}$ valorisation.

EDA involves the protonation of ethylene by Brønsted acid sites (BAS) [2,3] and further reactions (oligomerisation and protolytic cracking) involving carbenium ions as 
intermediate. High temperature [3-6] and low olefin partial pressure $\left(\mathrm{P}_{\mathrm{C} 2 \mathrm{H} 4}\right)[4,6-10]$ have been reported to limit the oligomerisation reaction. For instance, the ethylene conversion at $475{ }^{\circ} \mathrm{C}$ under atmospheric pressure using dilute ethylene $\left(\mathrm{P}_{\mathrm{C} 2 \mathrm{H} 4}=0.013 \mathrm{MPa}\right)$ is only of $2 \%$ [7] over ZSM-5 (Si/Al = 103). On the other hand, over $83 \%$ of conversion was reported over the same catalyst at $350{ }^{\circ} \mathrm{C}$ with a $\mathrm{P}_{\mathrm{C} 2 \mathrm{H} 4}$ of $0.1 \mathrm{MPa}$ [8]. The intrinsic activity of Brønsted acid sites (BAS) in ethylene transformation depends on their density, more precisely on the concentration of next nearest neighbours (NNN) of $\mathrm{Al}$ centres. Indeed, protonic acid pair sites ( $\mathrm{Al}$ at $\mathrm{NNN}$ position) convert ethylene into aromatics, while isolated BAS are almost inactive at high temperature [2]. Noticeably, new active sites can be generated in situ during the EDA reaction, which correlates the formation of an active hydrocarbon pool (HCP) involving light aromatics (2-5 rings). In other words, once HCP is formed, the reaction mechanism turns from purely BAS catalysed to a dual active site catalysed reaction. Uslamin et al. supported this pathway by proposing a dual-cycle HCP based on isotope labelling experiments [5].

Keeping the crucial role of $\mathrm{HCP}$ in mind, coke formation during EDA can result in catalyst deactivation [11]. Indeed, as light alkenes undergo fast condensation reactions (oligomerisations, polymerisations, cyclisations, hydrogen transfers, etc.), heavy products, which remain trapped within the zeolite micropores, can be formed [12,13]. On the opposite, benzene, toluene, and even naphthalene are much less reactive in acid catalysis, as they are neither bulky nor basic enough to be irreversibly retained on the zeolite catalyst. Moreover, thermal oligomerisation and (or) cracking of ethylene is thermodynamically more favourable than poly-condensation of benzene at $700{ }^{\circ} \mathrm{C}$. Song et al. confirmed ethylene as the main coke source using a three-layer fixed-bed mode reactor [14]. In brief, coking results from the transformation of olefins, which are intermediate products of the ethylene aromatisation, rather than from BTX polymerisation.

Hence, the control of zeolite deactivation induced by coke deposition requires the shortening of the diffusion path length of the zeolite. In this context, the most efficient way to reduce the diffusion path lengths is to engineer nano-sized zeolites featuring intracrystalline mesopores $[15,16]$.

The present study is devoted to the transformation of ethylene (EDA) on protonic H-ZSM-5 zeolite under the same operating conditions used for methane dehydroaromatisation reaction (MDA), i.e., $700{ }^{\circ} \mathrm{C}$, long contact times (0.6-1.1 s), and feed of $5 \mathrm{~mol} \%$ ethylene diluted in $\mathrm{N}_{2}$ at atmospheric pressure $[3,17,18]$. This study further focuses on the nature of coke and its impact on the textural and acidic properties of the zeolite, and on assessing the impact of the diffusion path length on catalyst activity, selectivity, and stability.

\section{Results}

\subsection{Materials Characterisation}

Micro- and nano-sized ZSM-5 zeolites ( $\mathrm{M}$ and N, respectively) were characterized by Inductively coupled plasma mass spectrometry (ICP), $\mathrm{N}_{2}$ physisorption at $77 \mathrm{~K}$, transmission electron miscoscopy (TEM), and Fourier Transform InfraRed spectroscopy (FTIR). Table 1 summarizes their main properties. The $\mathrm{M}$ sample features an average crystal size of $0.5 \mu \mathrm{m}$ and a microporous volume typical for MFI $\left(0.18 \mathrm{~cm}^{3} \mathrm{~g}^{-1}\right)$ [19]. The $\mathrm{N}$ zeolite presents substantial inter-crystalline mesopore volume $\left(0.20 \mathrm{~cm}^{3} \mathrm{~g}^{-1}\right)$ resulting from aggregation. Although the $\mathrm{Si}-\mathrm{Al}$ ratio is similar for both samples, the number of Brønsted acid sites (BAS) probed by pyridine sorption/desorption at $150{ }^{\circ} \mathrm{C}$ is $25 \%$ lower on the N sample.

\subsection{Activity, Selectivity, and Stability}

Figure 1a displays the ethylene conversion at a function of time-on-stream (TOS) obtained on M zeolite at $700{ }^{\circ} \mathrm{C}$ with different contact times $(\tau)$ ranging from 0.06 to $1.10 \mathrm{~s}$. Under such operating conditions, a blank test run without catalyst, thus solely driven by thermal conversion revealed less than $3 \%$ conversion of $\mathrm{C}_{2} \mathrm{H}_{4}$ into butenes (isobutene and but-1-ene), of which a small fraction further cracks into propylene and methane. 
Table 1. Textural and acid properties of micro- (M) and nano-sized (N) H-ZSM-5 zeolites.

\begin{tabular}{ccc}
\hline Catalyst & M & $\mathbf{N}$ \\
\hline Crystal size $^{\mathrm{a}}(\mu \mathrm{m})$ & 0.50 & 0.045 \\
$\mathrm{~V}_{\text {micro }}{ }^{\mathrm{b}}\left(\mathrm{cm}^{3} \mathrm{~g}^{-1}\right)$ & 0.18 & 0.17 \\
$\mathrm{~V}_{\text {meso }}{ }^{c}\left(\mathrm{~cm}^{3} \mathrm{~g}^{-1}\right)$ & 0.09 & 0.20 \\
$\mathrm{Si} / \mathrm{Al}_{\text {global }}$ & 40 & 41 \\
{$\left[\mathrm{PyH}{ }^{+}\right]^{\mathrm{e}}\left(\mu \mathrm{mol} \mathrm{g}^{-1}\right)$} & 305 & 224 \\
{$[\mathrm{PyL}]^{\mathrm{f}}\left(\mu \mathrm{mol} \mathrm{g}^{-1}\right)$} & 46 & 67 \\
\hline
\end{tabular}

a Apparent crystal size determined using TEM micrographs (Figure S1, in supporting information); ${ }^{\mathrm{b}}$ micropore volume calculated using the $\mathrm{t}$-plot method; ${ }^{\mathrm{c}}$ Mesopore volume $=\mathrm{V}_{\text {total }}-\mathrm{V}_{\text {micro }}\left(\mathrm{V}_{\text {total }}\right.$ : volume adsorbed at $\left.\mathrm{p} / \mathrm{p}^{0}=0.99\right) ;{ }^{\mathrm{d}}$ Measured by ICP analysis; ${ }^{\mathrm{e}, \mathrm{f}}$ Concentrations of pyridine adsorbed on Brønsted $\left(\mathrm{PyH}^{+}\right)$and Lewis (PyL) acid sites, respectively, after evacuation at $150^{\circ} \mathrm{C}$.
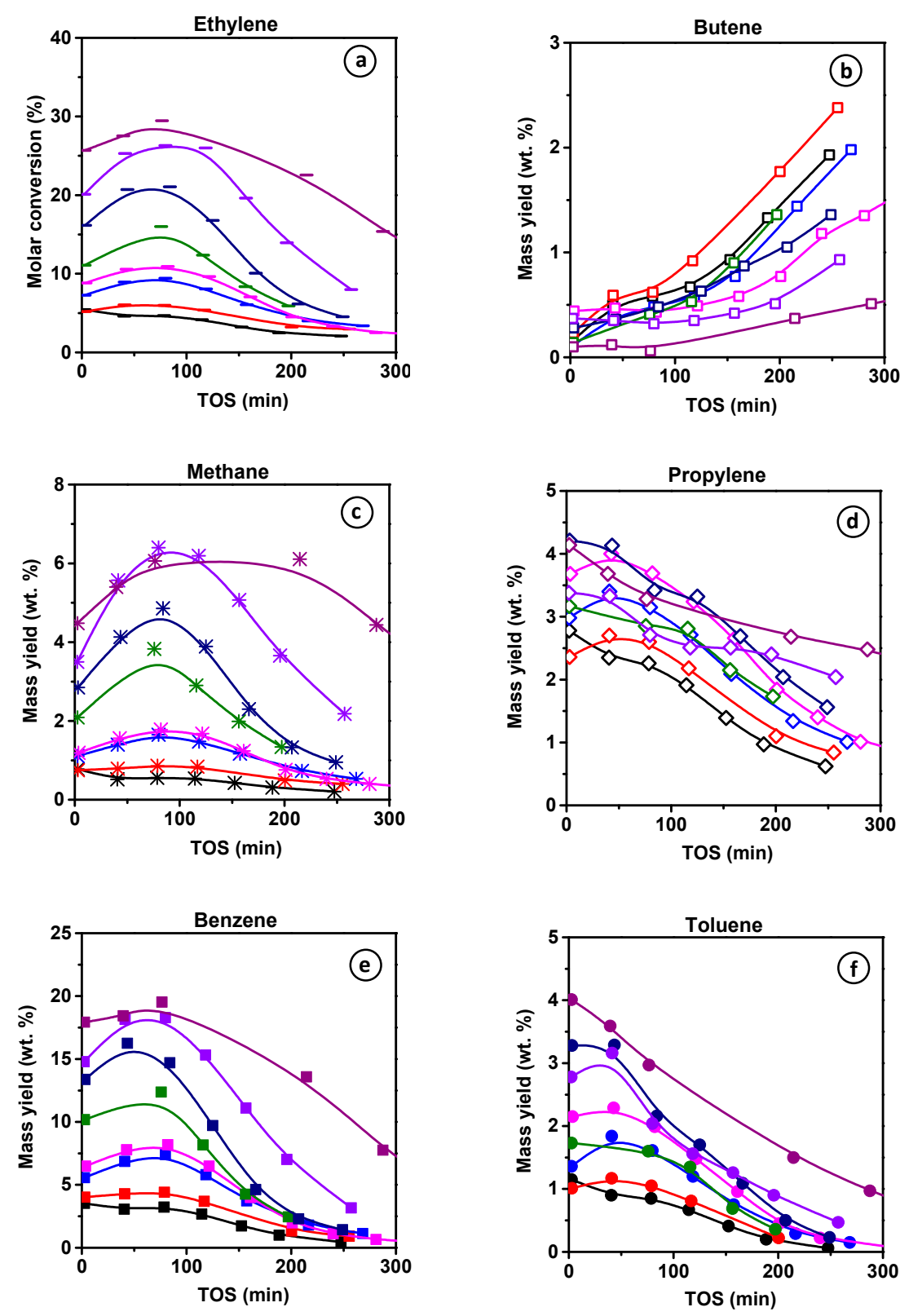

Contact time : $-0.06 \mathrm{~s}-0.09 \mathrm{~s}-0.19 \mathrm{~s}-0.22 \mathrm{~s}-0.37 \mathrm{~s}-0.45 \mathrm{~s}-0.75 \mathrm{~s}-1.10 \mathrm{~s}$

Figure 1. (a) Molar conversion of ethylene and mass yields of (b) butenes (isobutene and but-1-ene), (c) methane, (d) propylene, (e) benzene, and (f) toluene as a function of the time-on-stream obtained at $700{ }^{\circ} \mathrm{C}$ on the micro-sized (M) $\mathrm{H}-\mathrm{ZSM}-5$ zeolite with varying contact times. 
The partial ethylene conversion is due to the combination of high temperature, low partial pressure of the reactant, and low acid sites density $(\mathrm{Si} / \mathrm{Al}=40)$, which hinders the $\mathrm{C}_{2} \mathrm{H}_{4}$ oligomerisation on protonic sites [4-9]. The ethylene conversion increases with contact time $(\tau)$. Independently of $\tau$, ethylene conversion achieves a maximal value at approximately $80 \mathrm{~min}$ TOS, then decreases to reach the thermal conversion value (3\%), indicating a complete catalyst deactivation. Such a behaviour, involving an induction period followed by catalyst deactivation, is similar to what is observed in the MDA reaction on bifunctional Mo/H-ZSM- 5 catalyst $[3,20]$. The induction step is defined by the in situ generations of new active species with high catalytic activity. Volmer et al. have also observed an induction period during ethylene conversion at $700{ }^{\circ} \mathrm{C}$ on a H-ZSM-5 zeolite with a molar ratio of 40 . They explained the catalyst activation by the formation of a hydrocarbon pool [3].

Among the reaction products presented in Figure $1 \mathrm{~b}-\mathrm{f}$, benzene presents the highest molar yield. Similar proportions of propylene, methane, and toluene are detected, followed by butenes to a lesser extent, and traces of naphthalene. The effect of the induction period can be observed for the product mass yields of aromatics, methane, and, to a lesser extent, with a shorter contact time for propylene. Differently, $\mathrm{C}_{4} \mathrm{H}_{8}$ formation increases significantly at TOS values, which correspond to those of the catalyst deactivation. Butene evolution is hence a deactivation marker.

Figure 2a shows the evaluation of the kinetic rate constants for ethylene transformation (assuming a first-order reaction) (i) on the bare Brønsted acid sites at $\mathrm{t}=2 \mathrm{~min}$, and (ii) on the new active phase generated in situ during the reaction, at maximal conversion, after ca. $80 \mathrm{~min}$ on stream. Independently of the nature of the active sites involved, the plots $\ln (1-X)$ vs. contact time, where $X$ is the ethylene conversion, gives a straight line corresponding to the equation: $-\ln (1-X)=r_{\text {uncat }}+k_{\text {cat }} \tau$. For both species, a $r_{\text {uncat }}$ value between of $0.03-0.04$ is achieved, corresponding to the $y$-intercept, which is due to the thermal conversion level previously inferred from blank experiments showing $3 \%$ of ethylene conversion at $700{ }^{\circ} \mathrm{C}$. These yet feature distinct slopes as a function of the maximal conversion, which is approximately twice as high at short TOS on bare BAS compared to HCP. Hence, two distinct kinetics constants can be evidenced, which strongly supports the existence of two distinct active phases. The first corresponds to the bare BAS and features a moderate kinetic constant of $0.195 \mathrm{~s}^{-1}$. The second active phase shows a two times higher activity and is generated in situ during the reaction. In accordance with the findings by Uslamin et al. [5], we assume that these active centers are related to the formation of HCP (hydrocarbon pool) made of small aromatic molecules. Hence, the induction, as mentioned earlier, corresponds to the transformation of ethylene into HCP. The ethylene transformation catalyzed by HCP is hence ca. two times faster than by BAS.
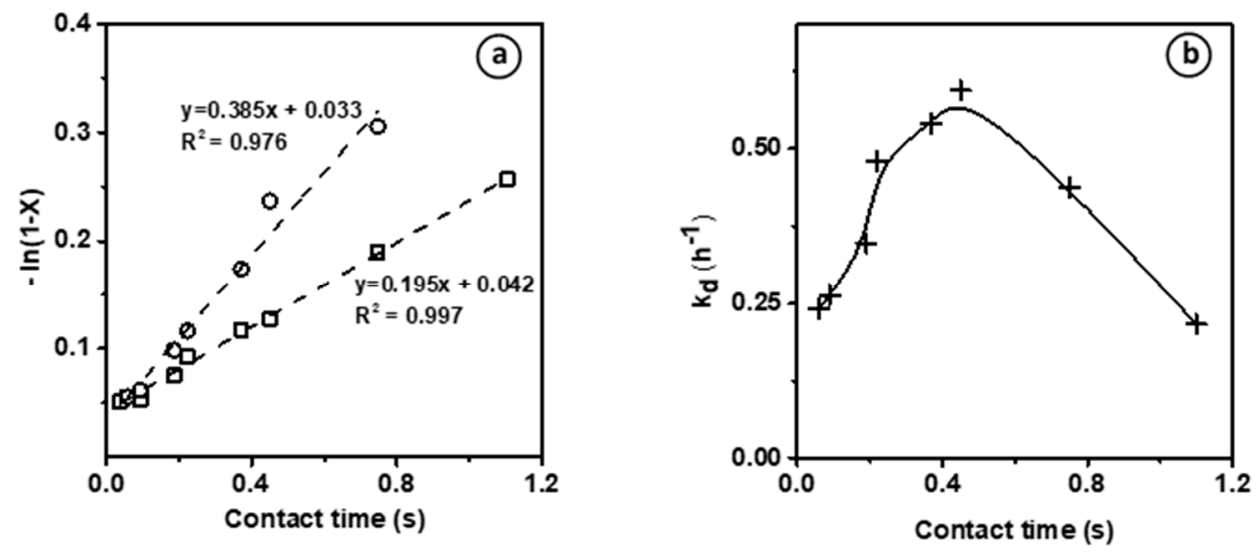

Figure 2. Test for the first-order rate equation established on the micro-sized (M) H-ZSM-5 zeolite, after 2 min (zeolite BAS) (squares) and after 40-80 min reaction (HCP) (circles) (a). Catalyst deactivation rate $\left(\mathrm{k}_{\mathrm{D}}\right)$ measured after the induction period as a function of the contact time $(\mathbf{b})$. 
The assumed change of the nature of the active sites during the reaction is expected not only to control the catalyst activity, but also its stability. This latter can be quantified by calculating the catalyst deactivation constant $\left(\mathrm{k}_{\mathrm{d}}, \mathrm{h}^{-1}\right)$ at end of the induction period after 40-80 min TOS, assuming a pseudo deactivation order of 1 [21]. The deactivation rate as a function of the contact time shows a bell-shaped curve, in which $\mathrm{k}_{\mathrm{d}}$ increases with the contact time, reaches a maximum and then decreases (Figure 2b). This mitigation of the deactivation could result from the formation at high conversion of reaction products that scavenge the catalyst surface (i.e., $\mathrm{H}_{2}$ ) or that are weakly reactive (alkanes, benzene) to acidic sites. Moreover, such behavior supports the hypothesis of the emergence of a new active phase during the reaction.

Figure 3 shows the conversion and molar yields as a function of the time-on-stream obtained on N ZSM-5. Unlike the micro-sized counterpart, the short diffusion path length $\left(D_{L}\right)$ characteristic of the small crystals avoids the induction period and significantly mitigates deactivation. Indeed, $\mathrm{k}_{\mathrm{d}}$ is about 5 times lower for the $\mathrm{N}$ catalyst $\left(0.05 \mathrm{~h}^{-1}\right)$ compared to the micro-sized sample.

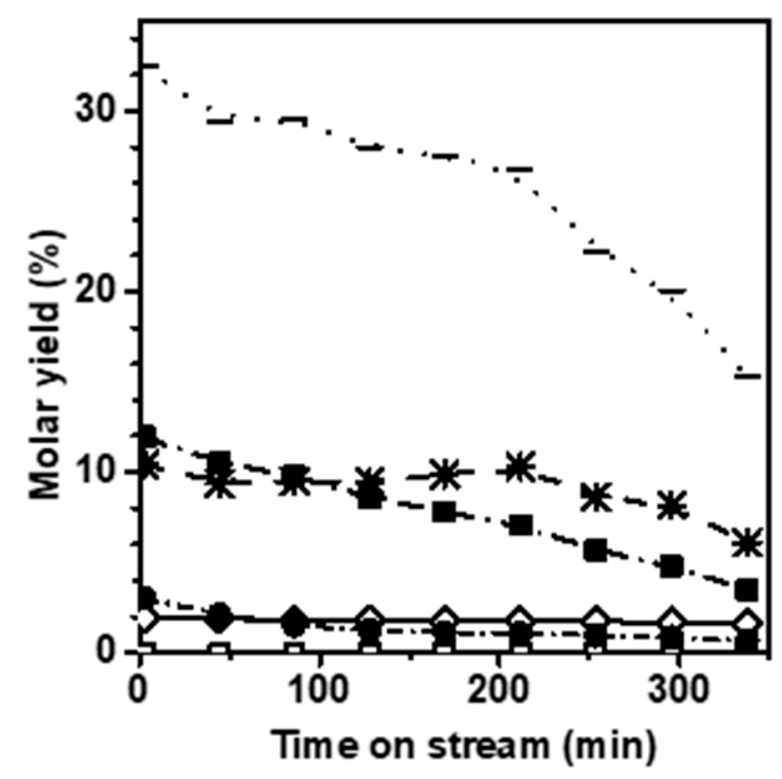

\section{- Conv - 米 $\mathrm{CH} 4 \prec-\mathrm{C} 3 \mathrm{H} 6 \cdots \square \cdots \mathrm{C} 4 \mathrm{H} 8-\mathrm{\Omega}-\mathrm{C} 6 \mathrm{H} 6-\bullet \cdot \mathrm{C} 7 \mathrm{H} 8$}

Figure 3. Molar yields observed for the EDA reaction as function of time-on-stream on nano-sized (N) H-ZSM- 5 zeolite at $700{ }^{\circ} \mathrm{C}$ with a contact time of $0.45 \mathrm{~s}$.

Figure 4 compares the molar yields of the main products: benzene, methane, propylene, and toluene as a function of the conversion (i) at low TOS (operated by zeolite BAS) and (ii) at TOS corresponding to the maximal conversion value, which we assume to be operated by HCP. The product selectivity profile remains identical in both cases, namely short TOS and maximum conversion, revealing that the reaction scheme is the same on BAS and HCP. However, the mechanism of the transformation is necessarily different in so far as light aromatics (HCP) participate in ethylene dimerization via the paring reaction, whereas dimerization on BAS implies the formation of an unstable primary carbenium ion. The alkylation of butene by ethylene or propylene followed by a cyclisation reaction occurs on the acid site and involves secondary carbenium ions. 


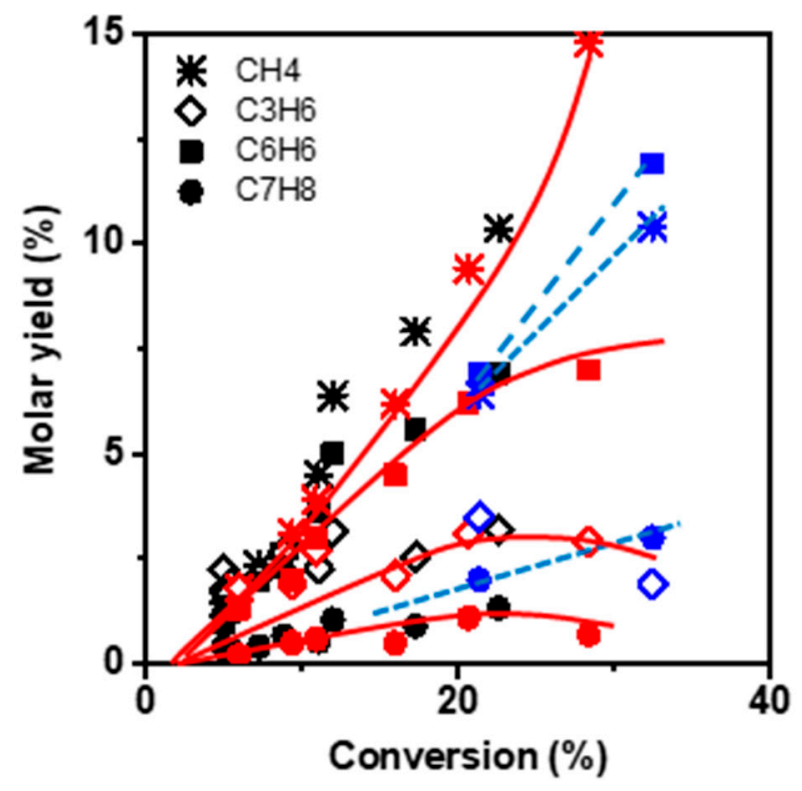

Figure 4. Molar yields of methane, propylene, benzene and toluene obtained on the micrometer-sized zeolite $(\mathrm{M})$ as a function of the conversion obtained on Brønsted acid sites (initial conversion, TOS = $2 \mathrm{~min}$, black symbol), on hydrocarbon pool (highest conversion, TOS $=40 \mathrm{~min}$, red symbol), and on the nano-sized $(\mathrm{N})$ zeolite (initial conversion, TOS $=2 \mathrm{~min}$, blue symbol).

Methane, benzene, propylene, and toluene appear as secondary products after $2 \%$ conversion (extrapolated value). This can be ascribed to the non-catalytic transformation of ethylene and the formation of the primary product butene, resulting from ethylene dimerization. At low conversion, the molar ratio of $\mathrm{CH}_{4}-\mathrm{C}_{3} \mathrm{H}_{6}$ is slightly lower than one, indicating that only a minor fraction of propylene reacts with butene to form toluene. With increasing conversion, the $\mathrm{CH}_{4}-\mathrm{C}_{3} \mathrm{H}_{6}$ molar ratio gradually deviates from unity. Indeed, at $20 \%$ conversion a bifurcation point is observed for which the methane yield increases with growing conversion, while the slope of $\mathrm{C}_{3} \mathrm{H}_{6}$ yield decreases. The methane yield keeps increasing with conversion, even though the BAS density at the zeolite surface significantly lowered during the reaction.

Besides, both propylene and toluene yields achieve a maximum of $20 \%$ conversion before stabilizing and finally declining (Figure 4). Therefore, $\mathrm{CH}_{4}$ does not result from a cracking mechanism but more likely from the dealkylation of toluene [2]. The aromatisation requires either an intra-molecular dehydrogenation (DH: $\mathrm{C}_{6} \mathrm{H}_{12} \leftrightharpoons \mathrm{C}_{6} \mathrm{H}_{6}+3 \mathrm{H}_{2}$ ) or an inter-molecular hydrogen transfer $\left(\mathrm{HT}: \mathrm{C}_{6} \mathrm{H}_{12}+3 \mathrm{C}_{2} \mathrm{H}_{4} \leftrightharpoons \mathrm{C}_{6} \mathrm{H}_{6}+3 \mathrm{C}_{2} \mathrm{H}_{6}\right)$. The HT mechanism involves alkanes as by-products; thereby, it is possible to identify which mechanism is at work by tracking the production of alkanes. In the present case, the alkane yield at low conversion is low, while at high conversion values, the alkanes (mainly ethane) yield becomes significant and further grows with increasing TOS (Figure S2, in Supplementary Materials). This change indicates that deactivation results from the formation of less reactive molecules catalysed on BAS.

The reduction in zeolite crystal size impacts the selectivity at high conversion. The methane and benzene yields are lower and higher, respectively, than those obtained on the M zeolite. This difference suggests the limitation of toluene dealkylation (Figure 4).

Scheme 1 proposes a reaction path by considering the evolution of primary or secondary products and the occurrence of side-reactions (toluene dealkylation and intermolecular hydrogen transfer). 


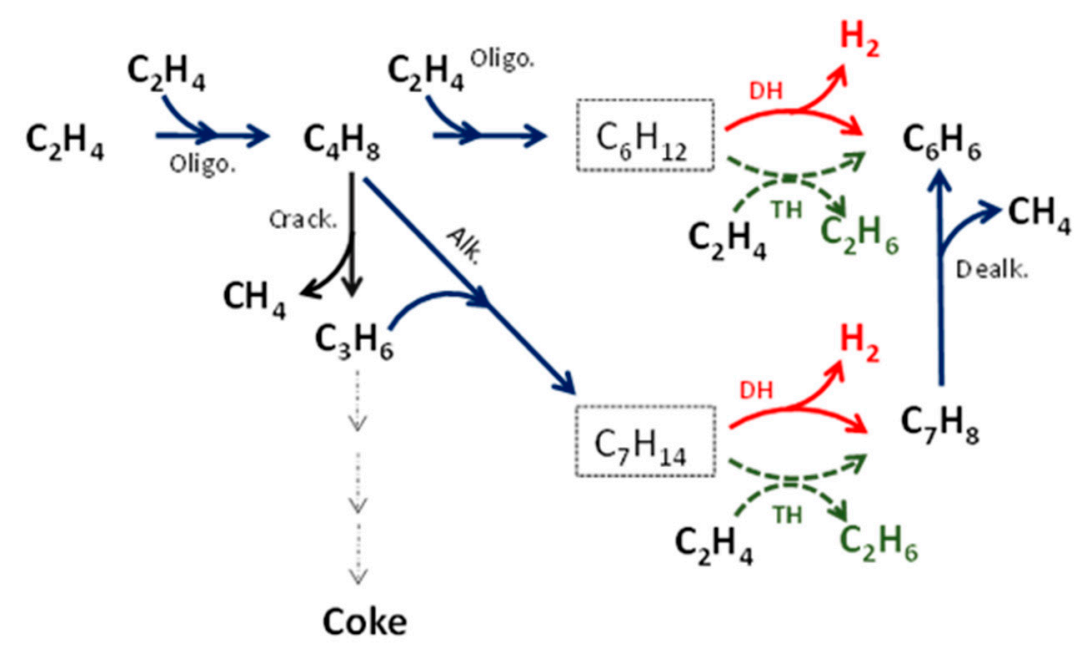

$\mathrm{DH}$ : Dehydrogenation

HT : Hydride transfer (high conversion) Alk/oligo: Alkykation/Oligomerisation

Dealk Dealkylation

Crack oracking

Scheme 1. Proposed reaction scheme of ethylene transformation on H-ZSM-5 zeolite at $700{ }^{\circ} \mathrm{C}$.

\subsection{Characterisation of Carbon Deposits}

To investigate the role of carbon deposits in either promoting the catalytic activity (HCP) or causing catalyst deactivation (coke), spent catalysts were collected at key steps of the reaction, namely (i) right after the induction period (20 min), (ii) after achieving the highest conversion value (80 $\mathrm{min}$ ), (iii) before total deactivation (180 $\mathrm{min}$ ), and (iv) after complete deactivation (360 min). The reaction was run at $0.45 \mathrm{~s}$ contact time (Figure $\mathrm{S} 3$ in Supplementary Materials) and stopped at the desired time. The reactor was then cooled to room temperature under $\mathrm{N}_{2}$ flow, and the spent catalyst was collected for characterisation. Moreover, the effect of the diffusion path length and mass transfer on the carbon deposit speciation was evaluated through a systematic comparison $\mathrm{M}$ and $\mathrm{N}$ zeolites. Figure 5 reports the coke content, the residual micropore volume, the remaining BAS content, and residual microporous volume for each of the reaction steps mentioned above.

In both $\mathrm{M}$ and $\mathrm{N}$ materials, the coke formation follows the first stage with a high rate and a subsequent slower growth regime as TOS $>80 \mathrm{~min}$. (Figure $5 \mathrm{a}, \mathrm{b}$ ) At TOS $=80 \mathrm{~min}$, significant coke amounts are formed in both $\mathrm{M}(5.5 \mathrm{wt} . \%)$ and $\mathrm{N}(10 \mathrm{wt} . \%)$ catalysts. At TOS > 80 min linear increase in coke content continues, despite complete deactivation of $\mathrm{M}$. As the highest ethylene conversion value is reached on $\mathrm{M}$ zeolite (TOS = $80 \mathrm{~min}$; $5.5 \mathrm{wt} . \%$ coke), more than $85 \%$ of BAS are poisoned, but the reduction in micropore volume is below 50\% (Figure 5c). This result validates our assumption that the observed induction period is due to the generation of a pool of small aromatic molecules (HCP) adsorbed on the zeolite walls by reaction with BAS sites while having a moderate impact on the overall microporous volume. A complete loss of BAS and $\mathrm{V}_{\text {micro }}$ is observed when coke deposit reaches $7 \mathrm{wt}$.\% (extrapolated value) and $15 \mathrm{wt} . \%$, respectively (Figure 5c). The molar weight of the coke $\left(M_{\text {coke }}^{\mathrm{HCP}}\right)$ constituting the HCP was calculated assuming that one coke molecule neutralized one BAS. As such, $M_{\text {coke }}^{H C P}$ increases from 130 to $220 \mathrm{~g} \mathrm{~mol}^{-1}$, which corresponds approximately to the molar weight of naphthalene and pyrene, respectively.

The absence of diffusion limitation on the nano-sized $(\mathrm{N})$ zeolite may seem inconsistent with the higher coking rate and higher coke content measured on N (Figure 5b) compared to $\mathrm{M}$. (Figure 5a). This contradiction can be explained by the fact that coke precursors are easily trapped on the numerous silanol groups located on the outer surface of $\mathrm{N} \mathrm{[16].}$ Lakiss et al. have shown that such external coke has little impact on the selectivity and none on the stability of the catalyst.

The faster development of HCP on $\mathrm{N}$ zeolite than $\mathrm{M}$ zeolite is consistent with the faster reduction in micropore volume (Figure $5 c, d$ ). The induction period on the M catalyst reveals that substantial diffusion limitations occur during the HCP formation. Moreover, 
these intracrystalline diffusion resistances impact the kinetic desorption of products, which favors the growth of coke, leading to catalyst deactivation. Indeed, Cui et al. have shown the MDA reaction on Mo/ZSM- 5 catalysts the existence of three rate-controlling regions. These reaction steps correspond to external mass transfer, intracrystalline diffusion, and kinetic desorption regimes [22].
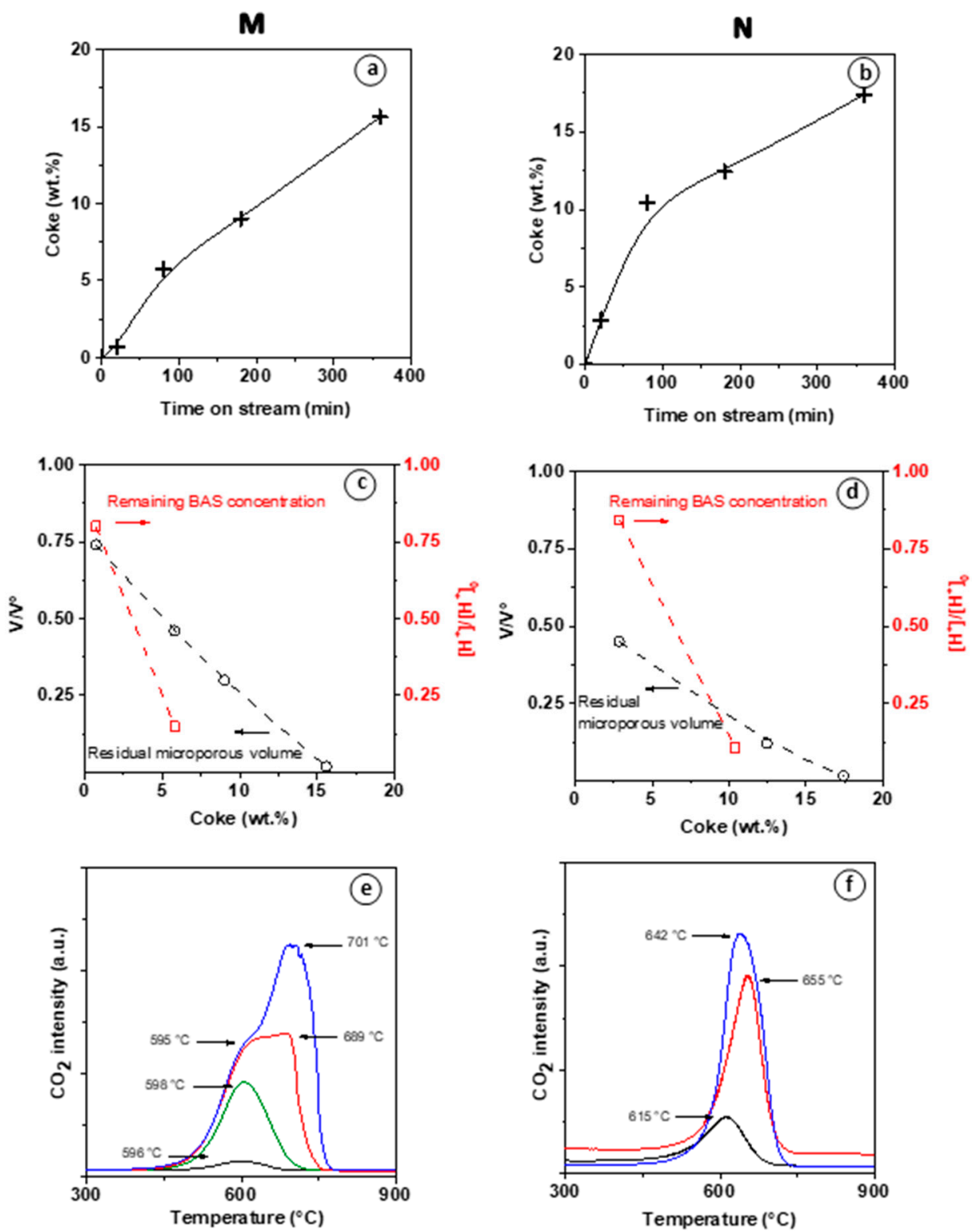

Figure 5. Coke content as a function of time-on-stream on the micro- (a) and nano-(b) sized zeolites. Residual micropore volume and BAS as a function of coke content on $\mathrm{M}(\mathbf{c})$ and $\mathrm{N}(\mathbf{d})$ catalysts. $\mathrm{CO}_{2}$ profile of coke combustion as a function of oxidation temperature for spent $\mathrm{M}(\mathbf{e})$ and $\mathrm{N}(\mathbf{f})$ catalysts after several time-on-stream values (black $=20 \mathrm{~min}$, green $=80 \mathrm{~min}$, red $=180 \mathrm{~min}$, blue $=360 \mathrm{~min}$ ) .

Figure 5e,f show the $\mathrm{CO}_{2}$ profiles resulting from the temperature-controlled coke burn-off on spent $\mathrm{M}$ and $\mathrm{N}$ zeolites. Note that no $\mathrm{CO}$ was detected during the operation. Low intensity of the water signal indicates poor hydrogen content of the coke. The $\mathrm{CO}_{2}$ profiles of the catalysts collected at TOS $=80 \mathrm{~min}$ (at the end of the induction period of M) display a low (M) to moderate intensity (N) peak at ca. $600{ }^{\circ} \mathrm{C}$. Vollmer et al. observed also for EDA on a H-ZSM-5, a coke oxidation peak at ca. $650{ }^{\circ} \mathrm{C}$ [3]. This high temperature is associated with diffusion-limited combustion of coke deposited in the zeolite micropores [23-25]. The $\mathrm{CO}_{2}$ profiles collected after 180 and $360 \mathrm{~min}$ TOS show 
an additional, higher temperature component. This shoulder is particularly noticeable in the $\mathrm{CO}_{2}$ production profile of $\mathrm{M}$ recovered after $180 \mathrm{~min}$ TOS (red line, Figure 5e), showing the co-existence of two components at $\sim 600$ and $\sim 700{ }^{\circ} \mathrm{C}$. In general, at TOS ranging from 80 to $120 \mathrm{~min}$, a single peak is detected around $600{ }^{\circ} \mathrm{C}$, which intensity increases with carbon content. At TOS $\geq 180 \mathrm{~min}$, a second peak appears and increases with TOS, while the first peak remains stable. On the N catalyst, the co-existence of distinct coke species is less pronounced. However, a moderate shift towards higher temperatures occurs upon varying the TOS from 20 to $180 \mathrm{~min}$. The peak assignment is possible from the chemical composition of the coke. The coke combustion is more driven by its aromaticity degree of polycyclic hydrocarbons rather than by their accessibility to oxygen. Indeed, the molecules trapped within the micropores burn at a lower temperature compared to heavy coke molecule on the external surface. Therefore, the lower combustion temperature on $\mathrm{N}$ zeolite compared to $\mathrm{M}$ zeolite $\left(\mathrm{ca} .50^{\circ} \mathrm{C}\right.$ ) suggests a lower aromaticity degree of the external coke (Figure $5 \mathrm{c}-\mathrm{f}$ ).

A further investigation of the speciation of the coke trapped inside the M zeolite pores at each step was made using liquid-liquid extraction of the mineralized zeolite matrix and the subsequent analysis of both the organic phase and the solid residual. The organic phase embeds the soluble $\left(\mathrm{C}_{\text {soluble }}\right)$, while the solid residual contains the insoluble $\left(\mathrm{C}_{\text {insoluble }}\right)$ coke fraction. GC-MS (Gas chromatography mass spectroscopy) analysis of the soluble coke fraction shows that the formation polyaromatic compounds: naphthalene, anthracene, phenanthrene, pyrene, and benzo(e)pyrene, occurs during the induction period (Figure S4 in Supplementary Materials). Before and after complete deactivation (3 and $6 \mathrm{~h}$ ), the fraction of polycyclic hydrocarbons composed of 2 to 5 aromatic cycles disappear. This disappearance occurs despite the increase in the overall coke content (Figure 5a). Therefore, deactivation is likely linked to a drastic change of carbon speciation. The characterisation of soluble coke by MALDI-TOF/MS (Matrix Assisted Laser Desorption Ionization-Time of Flight Mass Spectroscopy) reveals a limited number of heavy molecules (Figure 6a). It is worth indicating that the odd masses are due to the protonation of aromatic molecules by dithranol (MW: $226 \mathrm{~g} \mathrm{~mol}^{-1}$ ). Traces of heavy coke molecules appear from $80 \mathrm{~min}$ of reaction with molar weights of 474,556 , and $684 \mathrm{~m} / \mathrm{z}$, which corresponds to the chemical formulas $\mathrm{C}_{37} \mathrm{H}_{30}, \mathrm{C}_{43} \mathrm{H}_{40}$, and $\mathrm{C}_{53} \mathrm{H}_{48}$, respectively. The weight distribution is very different with the one obtained on ethanol transformation at $350{ }^{\circ} \mathrm{C}$ [25]. At low temperature the coke is very alkykated while at high temperature as dealkylation of aromatic rings occurs, the number of alkyl groups is limited.

Coke molecules are chemically reactive, and their interaction with reaction products results in continuous growth until they reach the size of the zeolite pores. The trapped molecules participating in $\mathrm{HCP}$, such as pyrene and benzopyrene, react with cyclohexane and tetralin, yielding hydrogen as a by-product (Scheme 2). Note that cyclohexane and tetralin are present as reaction intermediates to form benzene and naphthalene, respectively. The spent catalyst placed directly onto the mass spectrometer's target (LDI-TOF) allows characterizing the external coke. In the absence of the matrix (hydroxyanthrone), the molar masses of volatilized molecules are even (Figure $6 \mathrm{~b}$ ). The external coke appears after $3 \mathrm{~h}$ of reaction. The molecules located on the outer surface are heavier than those trapped within the zeolite micropores due to the absence of steric constraints limiting their growth. Their molar weight ranges from 448 up to $1310 \mathrm{~m} / \mathrm{z}$, which might correspond to polycyclic aromatic hydrocarbons with 35 to 115 carbons. Despite the wide range, the number of possible molecules is somewhat limited (5-10). Moreover, the spectrum after $6 \mathrm{~h}$ displays a mass loss sequence of $184 \mathrm{~m} / z$, which could correspond to hexahydroanthracene. This sequence suggests that the coke growth mechanism involves the polymerisation of hexahydroanthracene units, probably via a free-radical mechanism [26].

As the heavy coke overgrows the external surface of the crystals, it blocks the access of reactant molecules to the zeolite channels, which translates into a loss of accessible microporous volume, as shown in Figure 5b. Scheme 2 summarizes the growth sequence of coke molecules within the micropores and on the external surface. To the best of our 
knowledge, this work provides the first evidence of coke growth on the outer zeolite surface, mostly driven by a condensation mechanism.

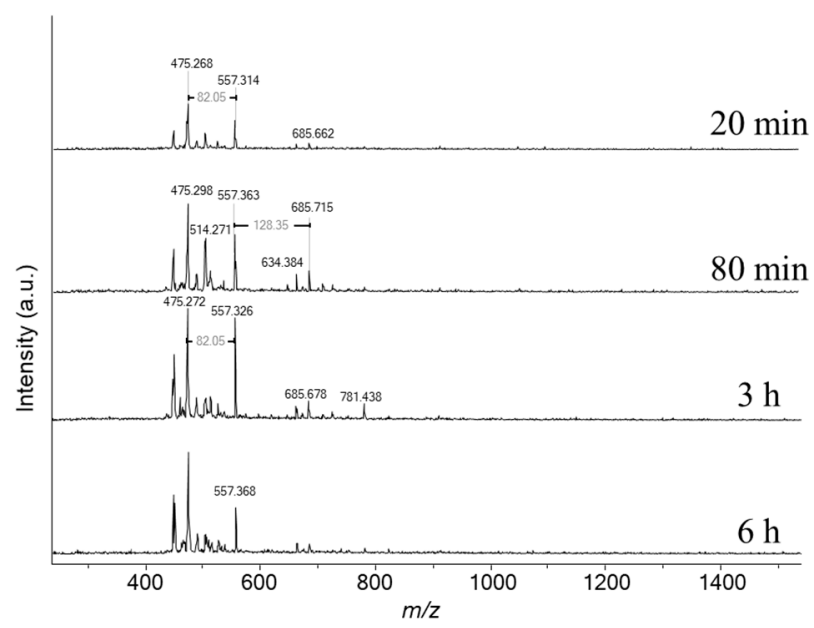

a

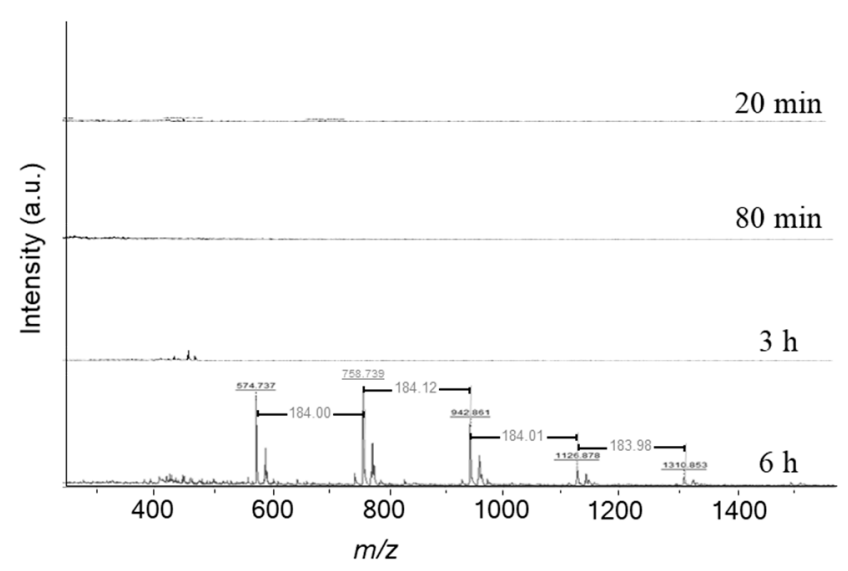

b

Figure 6. Evolution of MALDI-TOF mass spectrum of (a) the soluble coke (liquid fraction) and (b) LDI-TOF MAS of solid fraction extracted from spent M catalyst collected at different TOS.

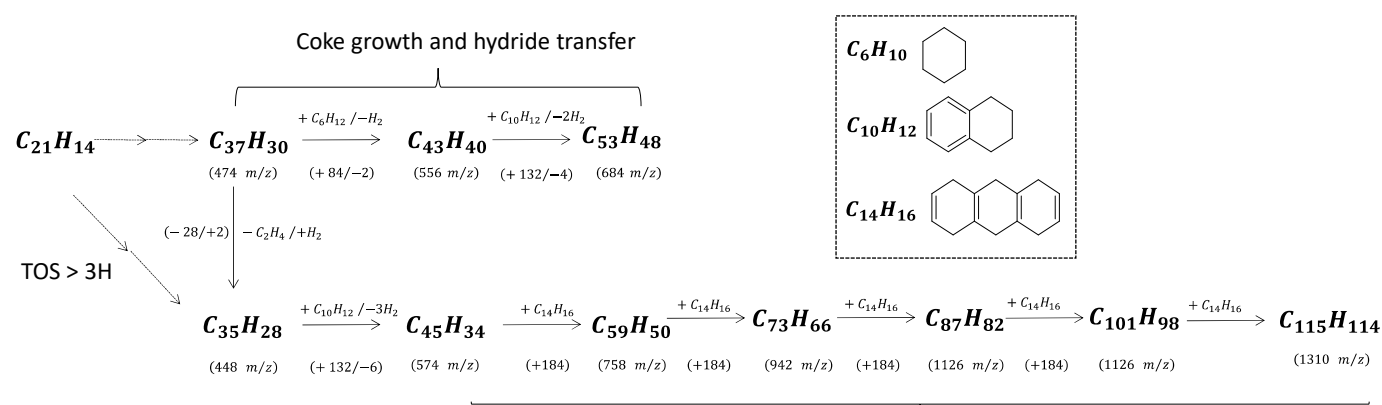

Polymerization

Scheme 2. A proposed sequence of the coke growth within micropores and on the external crystal surface of M zeolite.

\section{Materials and Methods}

Catalysts preparation: The mechanisms of ethylene transformation and deactivation were investigated over a micro-sized $\mathrm{NH}_{4}-\mathrm{ZSM}-5$ zeolite supplied by Zeolyst International (Delfzijl, Netherlands). Its protonic form, denoted as $\mathrm{M}$, was obtained by calcination at $500{ }^{\circ} \mathrm{C}$ for $8 \mathrm{~h}\left(5^{\circ} \mathrm{C} \mathrm{min}{ }^{-1}\right)$ under synthetic air. The nano-sized $\mathrm{NH}_{4}-\mathrm{ZSM}-5$ zeolite provided by Clariant (Clariant Produkte (Deutschland) GmbH, Munich, Germany), denoted as $\mathrm{N}$ after calcination in the same conditions as mentioned above, was also studied. 
Catalytic experiments: The catalytic tests were carried out in a continuous flow fixed bed reactor at $700{ }^{\circ} \mathrm{C}$ under atmospheric pressure. Before the activity test, the catalysts were sieved to obtain homogeneous particles with a grain size of $0.2-0.4 \mathrm{~mm}$. The sample, deposited on a layer of glass wool in the quartz reactor, was first activated under $100 \mathrm{~mL} \mathrm{~min}{ }^{-1}$ of $\mathrm{N}_{2}$ at $700{ }^{\circ} \mathrm{C}$. A gas mixture of ethylene diluted in $\mathrm{N}_{2}\left(5 \% \mathrm{C}_{2} \mathrm{H}_{4} / \mathrm{N}_{2}\right.$, $\mathrm{P}_{\mathrm{C} 2 \mathrm{H} 4}=50 \mathrm{hPa}$ ) was fed into the reactor. Depending on the test, the flow rate (from 50 to $200 \mathrm{~mL} \mathrm{~min}^{-1}$ ) and the mass of catalyst (from 0.2 to $1 \mathrm{~g}$ ), were varied. The resulting contact times were comprised between 0.06 and $1.10 \mathrm{~s}$. The feed gas composition and the reaction products were monitored by on-line gas chromatography using a 7890A GC (Agilent Technologies, (Santa Clara, CA, USA)) equipped with a FID detector and a CP-Sil PONA CB column $(100 \mathrm{~m} \times 0.25 \mathrm{~mm} \times 0.5 \mu \mathrm{m})$. The ethylene conversion and molar yields are calculated without internal standard but directly from the area of the GC peaks. Ethylene conversion $(X)$ and molar product yields $\left(Y_{n}\right)$ are calculated according to equation 1et 2, respectively, where $S_{C_{n}}$ denotes the surface area peak of the molecule $n, x$ the number of carbons in the molecule:

$$
\begin{gathered}
X=\frac{\sum_{n} S_{c_{n}}-S_{c_{\text {ethylene }}}}{\sum_{n} S_{c_{n}}} \times 100 \\
Y_{n}=\frac{\frac{S_{c_{n}}}{n}}{\sum_{n} \frac{S_{c_{n}}}{n}} \times 100
\end{gathered}
$$

Fresh and spent catalysts characterisation: The spent catalyst was recovered after cooling the reactor to RT under $\mathrm{N}_{2}$ flow. The porosity and external surface area of the zeolites were determined by nitrogen adsorption measurements at $-196{ }^{\circ} \mathrm{C}$ using an automatic ASAP 2010 apparatus from Micromeritics (Merignac, France). Before $\mathrm{N}_{2}$ adsorption, the fresh samples were degassed under vacuum at $100^{\circ} \mathrm{C}$ for $1 \mathrm{~h}$ and $400{ }^{\circ} \mathrm{C}$ for $10 \mathrm{~h}$. The spent catalysts were submitted to milder degassing at $150{ }^{\circ} \mathrm{C}$ for $1 \mathrm{~h}$, to avoid the coke removal from the zeolite. The total volumes were measured at $\mathrm{p} / \mathrm{p}^{0}=0.99$, while the microporous volumes and the external surfaces were determined by the t-plot method.

The zeolite crystal size was characterized by Transmission Electron Microscopy (TEM) using a Philips CM 120 microscope equipped with a $\mathrm{LaB}_{6}$ filament.

The acid properties of the materials were evaluated by pyridine adsorption monitored by FT-IR spectroscopy (Nicolet Magna 550-FT-IR, ThermoFisher, (Illkirch, France) $2 \mathrm{~cm}^{-1}$ of resolution). The fresh samples were first pressed to give a self-supported wafer and then activated at $400{ }^{\circ} \mathrm{C}$ under a high vacuum. The protocol varied for the coked catalysts: the activation was carried out at $100^{\circ} \mathrm{C}$ for $2 \mathrm{~h}$ to avoid the desorption of compounds. Then, the adsorption step was carried out by adding an excess of pyridine $(200 \mathrm{~Pa})$ at $150{ }^{\circ} \mathrm{C}$ and a subsequent degassing, in order to eliminate the physisorbed pyridine. Pyridine interacts with acidic sites in a specific way to form either a pyridinium ions on Brønsted acid sites $\left(\mathrm{PyH}^{+}\right)$or a coordinated species on a Lewis acid sites (PyL), leading to the appearance of several vibration modes. Among all the bands, the ones at 1455 and $1545 \mathrm{~cm}^{-1}$ were used to determine the number of $\mathrm{PyL}$ and $\mathrm{PyH}^{+}$acid sites, respectively. The molar extinction coefficients used for the calculation, [27], are equal to $1.13\left(\mathrm{PyH}^{+}\right)$and $1.28 \mathrm{~cm} \mathrm{\mu \textrm {mol } ^ { - 1 }}$ (PyL).

Coke characterisation: The coke combustion was monitored by a SDT Q600 TA (Paris, France) thermogravimetric analyser coupled with a GA Hiden Analytical mass spectrometer. The spent catalysts were first heated to $90{ }^{\circ} \mathrm{C}$ for $1 \mathrm{~h}$ and then to $900{ }^{\circ} \mathrm{C}$ for $1 \mathrm{~h}$ under a $10 \% \mathrm{O}_{2} / \mathrm{Ar}$ flow $\left(100 \mathrm{~mL} \mathrm{~min}{ }^{-1}\right)$, with a heating rate of $20^{\circ} \mathrm{C} \mathrm{min}{ }^{-1}$. During this oxidative treatment, the evolutions of $\mathrm{CO}_{2}(\mathrm{~m} / z=44), \mathrm{CO}(\mathrm{m} / z=28)$, and $\mathrm{H}_{2} \mathrm{O}$ $(m / z=18)$ were recorded, allowing determine the carbon content from the coke.

The investigation of the chemical composition of coke was derived from an established methodology developed by Magnoux et al. [28]. The external surface soluble coke was extracted by washing the catalyst with dichloromethane $\left(\mathrm{CH}_{2} \mathrm{Cl}_{2}\right)$ under $10 \mathrm{MPa}$ of $\mathrm{N}_{2}$ using a Dionex ASE 350 apparatus (ThermoFisher, Illkirch, France). The coke molecules 
trapped in the zeolite pores were extracted by mineralisation of the catalyst with a $51 \%$ hydrofluoric acid (HF) solution at room temperature. After the dissolution of the aluminosilicate matrix, the acid solution is neutralized with sodium hydrogen carbonate $\left(\mathrm{NaHCO}_{3}\right)$ before adding $\mathrm{CH}_{2} \mathrm{Cl}_{2}$ to the solution for liquid-liquid extraction. Insoluble coke was recovered by filtration.

The different types of coke were characterized by GC-MS and LDI-TOF. After removing the polar compounds from the extract with SPE cartridges (silica phase), the molecules from the soluble and external cokes were identified by GC-MS (Thermo Electron DSQ with a DB5ms column).

The soluble and insoluble coke fractions were characterized by MALDI-TOF MS (Bruker, Palaiseau, France) on a Brüker Autoflex Speed mass spectrometer in a reflectron positive mode, where ions were generated by a $337 \mathrm{~nm}$ wavelength nitrogen laser. $10 \mathrm{mg}$ of the extract (soluble or insoluble coke fractions) was suspended in $500 \mu \mathrm{L}$ of tetrahydrofuran (THF) and was mixed with dithranol as MALDI matrix (6 g/L in THF). After sonication, about $0.5 \mu \mathrm{L}$ of this mixture was hand spotted onto the stainless-steel target and dried at room temperature. External coke was characterized by depositing the spent catalyst directly onto the target (LDI analysis). Analyses were achieved using pulsed ion extraction (delay time $130 \mathrm{~ns}$ ). The laser power was adjusted slightly above the threshold of desorption and ionisation target and the spectra were the sum of 40,000 shots. The spectra presented in this paper were from raw data with baseline correction and no signal smoothing. As for the external coke, the spent catalyst was directly deposited onto the target.

\section{Conclusions}

Ethylene dehydroaromatisation reactions on H-ZSM- 5 features an induction period due to the formation of an active hydrocarbon pool that catalyzes ethylene conversion into aromatics.

The ethylene conversion is faster through a series of paring reactions of the confined and alkylated aromatic rings than its dimerisation on the Brønsted acid sites involving an unstable primary carbenium ion. The product mass transfer resistance plays a crucial role in both induction and deactivation periods by slowing down the hydrocarbon pool formation and favoring its growth into an inactive, heavy coke. Thus, the crystal downsizing, which allows to reduce diffusion path lengths of tens of nanometers permits the instantaneous establishment of the HCP and prevents its growth, hence its deactivation.

Ethane and methane dehydroaraomatisation present a common feature, which is the induction period. Hence, the use of nano-sized zeolites could result crucial toward the development of a stable bifunctional Mo/ZSM- 5 catalyst for the methane dehydroaromatisation process.

Supplementary Materials: The following are available online at https:/ /www.mdpi.com/2073-434 4/11/2/282/s1, Figure S1: Transmission electron microscopy (TEM) images of the micro- (M) and nano-sized (N) H-ZSM-5 zeolites, Figure S2: Evolution of the different molar while time on stream at various contact times: (a) the ratio aromatic-olefin, (b) the ratio paraffin-olefin, and (c) the ratio methane-propylene, Figure S3: Ethylene transformation at $700^{\circ} \mathrm{C}$ and a contact time of $0.45 \mathrm{~s}$ as function of time-on-stream, for the micro-sized H-ZSM-5 zeolite (M), Figure S4: Evolution of mass spectrum of soluble coke extracted after running for different reaction times.

Author Contributions: Conceptualisation, L.P., validation, M.B. and A.B., writing-original draft preparation, A.B. and L.P.; writing-review and editing, L.P., A.S., E.B., N.B., and J.-F.P. supervision, project administration and funding acquisition, L.P. All authors have read and agreed to the published version of the manuscript.

Funding: A. Beuque, A. Sachse, E. Berrier, J.P. Paul, N. Batalha, and L. Pinard thank the European Union's Horizon 2020 research and innovation program for its funding under grant agreement No 814548. This publication only reflects the author's views and neither Agency nor the Commission are responsible for any use that may be made of the information contained therein. 


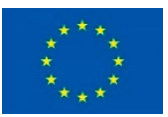

Acknowledgments: The authors acknowledge financial support from the European Union (ERDF) and "Région Nouvelle Aquitaine".

Conflicts of Interest: The authors declare no conflict of interest.

\section{References}

1. The Future of Petrochemicals: Growth Surrounded by Uncertainty. Available online: https://www2.deloitte.com/content/dam/ Deloitte/us/Documents / energy-resources/the-future-of-petrochemicals.pdf (accessed on 2 January 2021).

2. Bessell, S.; Seddon, D. The conversion of ethane and propene to higher hydrocarbons over ZSM-5. J. Catal. 1987, 105, 270-275. [CrossRef]

3. Vollmer, I.; Abou-Hamad, E.; Gascon, J.; Kapteijn, F. Aromatization of ethylene-Main intermediate for MDA? ChemCatChem 2020, 12, 544-549. [CrossRef]

4. Bonnin, A.; Comparot, J.D.; Pouilloux, Y.; Coupard, V.; Pinard, L. Mechanisms of aromatization of dilute ethylene on HZSM-5 and on Zn/HZSM-5 catalysts. Appl. Catal. A Gen. 2021, 611. [CrossRef]

5. Uslamin, E.A.; Saito, H.; Kosinov, N.; Pidko, E.; Sekin, Y.M.; Hensen, E.J. Aromatization of ethylene over zeolite-based catalysts. Catal. Sci. Technol. 2020, 10, 2774-2785. [CrossRef]

6. Dufresne, L.A.; Le Van Mao, R. Hydrogen back-spillover in the aromatization of ethylene on hybrid ZSM-5 catalysts. Catal. Lett. 1994, 25, 371-383. [CrossRef]

7. Gao, J.; Wei, C.; Dong, M.; Wang, G.; Li, Z.; Qin, Z.; Wang, J.; Fan, W. Evolution of Zn species on Zn/HZSM-5 catalyst under H2 pretreated and its effect on ethylene aromatization. Chem CatChem 2019, 11, 3892-3902. [CrossRef]

8. Ying, L.; Zhu, J.; Cheng, Y.; Wang, L.; Li, X. Kinetic modelling of C2-C7 olefins interconversion over ZSM-5 catalyst. J. Ind. Eng. Chem. 2016, 33, 80-90. [CrossRef]

9. Lukyanov, D.B. Development of kinetics models for reactions of light hydrocarbons over ZSM-5 catalysts. Experimental studies and kinetic modelling of ethane transformation and deactivation of HZSM-5 catalyst. Stud. Surf. Sci. Catal. 1999, 122, $299-306$.

10. Qiu, P.; Lunsford, J.H.; Rosynek, M.P. Characterization of Ga/ZSM-5 for the catalytic aromatization of dilute ethylene streams. Catal. Lett. 1998, 52, 37-42. [CrossRef]

11. Bonnin, A.; Pouilloux, Y.; Coupard, V.; Pinard, L. Deactivation mechanism and regeneration study of Zn/HZSM-5 catalyst in ethylene transformation. Appl. Catal. A Gen. 2021, 611. [CrossRef]

12. Guisnet, M.; Magnoux, P. Organic chemistry of coke formation. Appl. Catal. A Gen. 2001, 212, 83-96. [CrossRef]

13. Guisnet, M.; Ribeiro, F.R. Deactivation and Regeneration of Zeolite Catalysts. Photoorganocatalysis Org. Synth. 2011. [CrossRef]

14. Song, Y.; Xu, Y.; Suzuki, Y.; Nakagome, V.X.; Zhang, Z.-G. A clue to exploration of pathway of coke formation on Mo/HZSM-5 catalyst in the non-oxidative methane dehydroaromatization at 1073K. Appl. Catal. A Gen. 2014, 482, 387-396. [CrossRef]

15. Ngoye, F.; Lakiss, L.; Qin, Z.; Laforge, S.; Canaff, C.; Tarighi, M.; Valtchev, V.; Thomas, K.; Vicente, A.; Gilson, J.P.; et al. Mitigating coking during methylcyclohexane transformation on HZSM-5 zeolites with additional porosity. J. Catal. 2014, 320, 118-126. [CrossRef]

16. Lakiss, L.; Ngoye, F.; Canaff, C.; Gilson, J.-P.; Laforge, S.; Qin, Z.; Tarighi, M.; Thomas, K.; Valtchev, V.; Vicente, A.; et al. On the remarkable resistance to coke formation of nanometer-sized and hierarchical MFI zeolites during ethanol to hydrocarbons transformation. J. Catal. 2015, 328, 165-172. [CrossRef]

17. Mériaudeau, P.; Ha, V.T.T.; Tiep, L.V. Methane aromatization over Mo/H-ZSM-5 on the reaction pathway. Catal. Lett. 2000, 64, 49-51. [CrossRef]

18. Mériaudeau, P.; Tiep, L.V.; Ha, V.T.T. Aromatization of methane over Mo/H-ZSM-5 catalyst: On the possible reaction intermediates. J. Mol. Catal. A Gen. 1999, 144, 469-471. [CrossRef]

19. Batonneau-Gener, I.; Sachse, S. Detremination of the exact microporous volume and BET surface area in hierarchical ZSM-5. J. Phys. Chem. C 2019, 123, 4235-4242. [CrossRef]

20. Kosinov, N.; Wipkema, A.S.G.; Uslamin, E.; Rohling, R.; Coumans, F.J.A.G.; Mezari, B.; Parastaev, A.; Poryvaev, A.S.; Fedin, M.; Pidko, E.A.; et al. Confinde carbon mediating, dehydroaromatization of ethane over Mo/ZSM-5. Angew. Chem. Int. Ed. 2018, 57, 1016-1020. [CrossRef]

21. Wojciechowsky, B.M. A theoretical treatment of catalyst decay. Can. J. Chem. Eng. 1968, 46, 48-52. [CrossRef]

22. Cui, Y.; Xu, Y.; Suzuki, Y.Z.-G. Experimental evidence for three rate-controlling of the non-oxidative methane dehydroaromatization over Mo/HZSM-5 catalyst at 1073 K. Sci. Technol. 2011, 1, 823-829. [CrossRef]

23. Ma, D.; Wang, D.; Su, L.; Shu, Y.; Xu, Y.; Bao, I. Carbonaceaous deposition on Mo/HMCM-22 catalysts for methane aromatization: A TP technique investigation. J. Catal. 2002, 208, 260-269. [CrossRef]

24. Ma, D.; Lu, Y.; Su, L.; Xu, Z.; Tian, Z.; Xu, Y.; Lin, L.; Bao, X. Remarkable improvement on the methane aromatization reaction: A highly selective and coking resistant catalyst. J. Phys. Chem. B 2002, 106, 8524-8530. [CrossRef] 
25. Pinard, L.; Hamieh, S.; Canaff, C.; Madeira, F.; Batonneau-Gener, I.; Maury, S.; Delpoux, O.; Ben Tayeb, K.; Pouilloux, Y.; Vezin, H. Growth mechanism of coke on HBEA zeolite during ethanol transformation. J. Catal. 2013, 299, 284-297. [CrossRef]

26. Pinard, L.; Ben Tayeb, K.; Hamieh, S.; Vezin, H.; Canaff, C.; Maury, S.; Delpoux, O.; Pouilloux, Y. On the involvement of radical "coke" in ethanol conversion to hydrocarbons over HZSM-5 zeolite. Catal. Today 2013, 218-219, 57-64. [CrossRef]

27. Miranda, C.; Urresta, J.; Cruchade, H.; Tran, A.; Benghalem, M.; Astafan, A.; Gaudin, P.; Daou, T.J.; Ramirez, A.; Pouilloux, Y.; et al. Exploring the impact of zeolite porous voids in liquid phase reactions: The case of glycerol etherification by ter-butyl alcohol. J. Catal. 2018, 365, 249-260. [CrossRef]

28. Magnoux, P.; Roger, P.; Canaff, C.; Fouché, V.; Gnep, N.S.; Guisnet, M. New technique for the characterization of carbonaceous compounds responsible for zeolite deactivation. Stud. Surf. Sci. Catal. 1987, 34, 317-330. 